\title{
Conjugated linoleic acid, unlike other unsaturated fatty acids, strongly induces glutathione synthesis without any lipoperoxidation
}

\author{
Khelifa Arab ${ }^{1}$, Adrien Rossary ${ }^{2,3}$, Laurent Soulère ${ }^{4}$ and Jean-Paul Steghens ${ }^{2,3 *}$ \\ ${ }^{1}$ Divison of Toxicology and Cancer Risk Factors, German Cancer Research Center (DKFZ), Im Neuenheimer Feld 280, \\ 69120 Heidelberg, Germany \\ ${ }^{2} U F$ 21455, Oxidative Stress and Vitamins, Biochemistry Federation, E. Herriot Hospital, Lyon, France \\ ${ }^{3}$ EA 3090, Claude Bernard University Lyon 1, Lyon, France \\ ${ }^{4}$ Laboratoire de Chime Organique, UMR CNRS-UCBL 5181, Institut National des sciences appliquées, \\ 20 avenue A. Einstein, 69621 Villeurbanne, France
}

(Received 2 February 2006 - Revised 6 June 2006 - Accepted 19 June 2006)

\begin{abstract}
Enhancement of the redox status of cells is a cytoprotective strategy against oxidative damage. We recently showed that DHA upregulates glutathione (GSH) content via an induction of its related enzymes $\gamma$-glutamylcysteine ligase and glutathione reductase. In the present study, we investigated the effects of eight other fatty acids on the redox status and lipid peroxidation of human fibroblasts. After $48 \mathrm{~h}$, only arachidonic acid and conjugated linoleic acid (CLA) enhanced GSH content through an induction of $\gamma$-glutamylcysteine ligase. CLA was more potent than arachidonic acid in inducing GSH synthesis. For all the fatty acids tested, lipoperoxidation, estimated by cell malondialdehyde measurement, did not differ from that of controls at $48 \mathrm{~h}$ but dramatically increased at $7 \mathrm{~d}$, except for CLA. Lipoperoxidation is associated at $7 \mathrm{~d}$ with a high level of reactive oxygen species and with increased haemoxygenase- 1 and cyclooxygenase- 2 mRNA expression. As demonstrated by a tert-butylhydroperoxide cytotoxicity test, the GSH synthesis obtained with arachidonic acid is not sufficient to protect the cells, whereas this protective effect was obvious with CLA at $48 \mathrm{~h}$ as well as at $7 \mathrm{~d}$. The present results show that CLA is the only PUFA able to induce GSH synthesis without any change in oxidative balance, whereas an upregulation of cyclooxygenase- 2 by other PUFA is concomitant with an overproduction of malondialdehyde and reactive oxygen species. The particular hairpin conformation obtained for CLA by molecular modelling could account for this specific biological effect.
\end{abstract}

PUFA: Conjugated linoleic acid: Redox status: Antioxidant response: Glutathione: Cyclooxygenase-2: Haemoxygenase-1: Reactive oxygen species: Lipid peroxidation

An increased dietary consumption of $n-3$ PUFA elevates their incorporation into membrane phospholipids of cells or tissues. Thus, $n-3$ PUFA are claimed to exert protection against CVD and cancer. The molecular mechanisms of these effects are, however, still under study (Jump, 2002).

The potential for preventive actions in CVD was recently bolstered by the finding that PUFA, especially $n-3$ PUFA, have a protective effect on ischaemia-reperfusion in neuroprotection and an anti-inflammatory action (Pepe \& McLennan, 2002; Mukherjee et al. 2004). EPA (C20:5n-3) and DHA $(\mathrm{C} 22: 6 n-3)$ are usually consumed in small quantities and are therefore found in relatively low proportions in plasma and tissue lipids. An increased consumption of these fatty acids is, however, associated with their increased proportions in various blood and tissue lipid pools (Chan et al. 2003; Laidlaw \& Holub, 2003). Paradoxically, enrichment with $n$-3 PUFA is thought to enhance the susceptibility of tissues to oxidation by free radicals. The susceptibility of a particular tissue to oxidation is influenced by its PUFA and antioxidant content. Some studies have investigated the effects of dietary or supplemented PUFA on the susceptibility of lipoproteins or cells to oxidation, and have demonstrated a marked reduction in the lag phase for oxidation by PUFA (Oostenbrug et al. 1994; Song et al. 2000). Not all data, however, agree that $n-3$ PUFA increase overall susceptibility to oxidation, and it is not clear whether the two major $n$-3 PUFA in fish oil, EPA and DHA, are equally potent in decreasing oxidation (Higdon et al. 2000; Mori et al. 2003).

Lipid peroxidation generates highly reactive aldehydes, such as 4-hydroxynonenal and malondialdehyde (MDA), which are involved in some pathophysiological processes. 4-Hydroxynonenal could modulate protein activity by addition reactions to cysteinyl residues, a mechanism that may explain some gene regulations via lipid peroxidation (Levonen et al. 2004). PUFA serve as substrates for several enzymes in eicosanoid metabolism, and their products play huge roles in the homeostasis of peroxide. Three isoforms of cyclooxygenase (COX), also named prostaglandin endoperoxide $\mathrm{H}$ synthase, exist in mammalian tissues, and these enzymes oxygenate arachidonic acid (AA; 20:4n-6) to form a substrate required for prostaglandin synthesis. COX-1 is constitutive and generates

Abbreviations: AA, arachidonic acid; CLA, conjugated linoleic acid; COX, cyclooxygenase; $\gamma$-GCL, $\gamma$-glutamylcysteine ligase; GSH, glutathione; $\mathrm{H}_{2} \mathrm{DCF}-\mathrm{DA}$; 2',7'-dihydrodichlorofluorescein diacetate; HO-1, haemoxygenase-1; LA, linoleic acid; LLA; $\alpha$-linolenic acid; GLA, $\gamma$-linolenic acid; MDA, malondialdehyde; $\mathrm{OA}$, oleic acid; RA, arachidic acid; ROS, reactive oxygen species; t-BOOH, tert-butylhydroperoxide.

* Corresponding author: Dr Jean-Paul Steghens, fax +33 4721106 75, email jean-paul.steghens@chu-lyon.fr 
prostaglandins in response to hormone stimulation, whereas COX-2 is an inducible enzyme, expressed in response to stress stimuli such as cytokines and tumour promoters. The induction of COX-2 is consequently implicated in cellular damage and in several inflammatory diseases; another isoform, COX-3, which was recently discovered, is still under study (Smith et al. 2000; Ringborn et al. 2001).

Glutathione (GSH) is the main cellular antioxidant. As such, GSH is critical for maintaining cellular functions; it provides protection against increases in the level of reactive oxygen species (ROS; Meister, 1983). GSH is involved in detoxification processes via the conjugation of xenobiotics and lipid peroxidation products with $\gamma$-glutamyl $\mathrm{S}$ transferase. Its level is maintained by both a recycling of oxidised GSH by glutathione reductase and a de novo synthesis by $\gamma$-glutamylcysteine ligase ( $\gamma$-GCL), the rate-limiting enzyme in this synthesis. The transcription of the two subunits of $\gamma$-GCL seems to be regulated by dimeric transcription factors such as small Maf proteins and other bZIP family members, including Nrf 1 and 2. In addition, these transcription factors upregulate cytoprotective genes such as haemoxygenase-1 (HO-1; Wild et al. 1999; Leung et al. 2003). Another regulation by NFKB is involved in the transactivation of $\gamma$-GCL during induced stress (Urata et al. 1996). The involvement of these transcription factors in GSH homeostasis suggests that they are selfsensitive to the cell redox environment (Wu et al. 1996).

In the present report, we have investigated, on the one hand, the effects of fatty acids on the thiol redox status of cells and their protective effects against oxidative damage, and on the other hand, the involvement of lipid peroxidation in enhancing this damage.

\section{Materials and methods}

\section{Chemicals}

Chemicals were obtained as follows: arachidic acid (AA; $20: 0)$, oleic acid (OA; $18: 1 n-9)$, linoleic acid (LA; $18: 2 n-6)$, $\alpha$-linolenic acid (LLA, $18: 3 n-3)$, $\gamma$-linolenic acid (GLA; $18: 3 n-6$ ), AA (20:4n-6), conjugated LA (CLA; $18: 2$ [9Z, 11E]), EPA $(20: 5 n-3)$ and 4-hydroxynonenal were purchased from Cayman Chemical (Interchin, Montluçon, France); PBS, 2, $\alpha-$ aminobutyrate and L-glutamate from Sigma-Aldrich (Saint Quentin Fallavier, France); reduced GSH, ATP, phosphoenolpyruvate and pyruvate kinase from Roche (Meylan, France); 2', $7^{\prime}$-dihydrodichlorofluorescein diacetate $\left(\mathrm{H}_{2} \mathrm{DCF}\right.$ DA) from Fluoroprobe (Interchin); and Meth-Prep II from Alltech (Interchin). All other reagents were of analytical grade.

Fatty acid stock solutions $(150 \mathrm{mmol} / \mathrm{l})$ were prepared in $\mathrm{C}_{2} \mathrm{H}_{5} \mathrm{OH}$, divided into aliquots and stored under $\mathrm{N}_{2}$ in brown glass vials at $-20^{\circ} \mathrm{C}$. All concentrations are given in final concentrations in incubation or culture medium.

\section{Cell culture}

Human skin fibroblasts were a gift from Dr Damour of the Tissue and Cell Bank HCL, Hopital Edouard Herriot, Lyon, France. The human fibroblasts were grown in DMEM containing $10 \%$ FCS (Gibco; Pontoise, France) and $2.5 \mu \mathrm{g}$ fungizone/ $\mathrm{ml}, 98 \mathrm{IU}$ penicillin/ml and $98 \mu \mathrm{g}$ streptomycin/ml (Cambrex, Emerainville, France). Cultures were maintained at $37^{\circ} \mathrm{C}$ in a humidified atmosphere with $5 \% \mathrm{CO}_{2}$.

The culture medium was supplemented with each fatty acid at $30 \mu \mathrm{mol} / \mathrm{l}$ : the fatty acid stock solution was dissolved $1: 5000$ in culture medium, with the appropriate controls. Cells were grown for different periods of time, up to $7 \mathrm{~d}$, and the culture medium was changed every day. At $48 \mathrm{~h}$ or $7 \mathrm{~d}$, cells were harvested by trypsinisation and washed twice with PBS $1 \mathrm{X}$. Cells were collected in $500 \mu \mathrm{l}$ Tris- $\mathrm{HCl} 50 \mathrm{mmol} / \mathrm{l}, \mathrm{pH} 7.4$ and Tween 20 $0.2 \%$, and $50 \mu \mathrm{l}$ were processed immediately to measure oxidised and reduced GSH, as previously described (Steghens et al. 2003). For other tests, the cells were lysed with two successive freezing and thawing operations with $15 \mathrm{~s}$ sonication. The cell lysates were stored at $-20^{\circ} \mathrm{C}$ until analysis.

For fatty acid analysis, cells were collected after washing and lysed by repeated freezing and thawing in $500 \mu \mathrm{l}$ Tris$\mathrm{HCl} 50 \mathrm{mmol} / \mathrm{l}, \mathrm{pH} 7 \cdot 4$. Cell lysates were stored at $-80^{\circ} \mathrm{C}$ until analysis.

Cell lysate proteins were measured by bichromatic spectrophotometry (570 and $700 \mathrm{~nm}$ ) with bicinchonic acid (Pierce, Interchin) at $37^{\circ} \mathrm{C}$ on a Kone analyser (Thermo Electron, La Garenne-Colombes, France) with human albumin as standard.

\section{Fatty acid analysis}

Lipids were extracted from $200 \mu$ l cell extract (approximately $10^{6}$ cells) with chloroform-methanol $(2: 1 \mathrm{v} / \mathrm{v})$, with di-palmitoyl-d31-phosphatidylcholine as an internal standard. Fatty acid methyl esters were formed after hydrolysis by transmethylation of the lipids with Meth-Prep II. Analyses were carried out on an HP 5980 gas chromatograph (Agilent, Massy, France) equipped with a flame ionisation detector maintained at $220^{\circ} \mathrm{C}$, an $\mathrm{HP}$ 6980 auto injector (Agilent), a $1 \mathrm{~m}$ silanised precolumn and a $30 \mathrm{~m} \times 0.32 \mathrm{~mm} \times 0.2 \mu \mathrm{m} \quad \mathrm{SP} 2340$ fused silica capillary column (Supelco, Saint Quentin Fallavier, France). Results are expressed as $\mu \mathrm{mol} / \mathrm{million}$ cells.

\section{Thiol redox status}

Oxidized and reduced glutathione. GSH was measured by LC-MS as previously described (Steghens et al. 2003). The processed sample was diluted $1: 5(\mathrm{v} / \mathrm{v})$ in distilled water and subjected to LC-MS analysis.

$\gamma$-Glutamyl-cysteine ligase activity. The activity of $\gamma$-GCL was determined by a new kinetic LC-MS method (Chik et al. 2005). Briefly, after incubating the cell extract (three aliquots of $10 \mu \mathrm{l} \mathrm{each}$ ) at $37^{\circ} \mathrm{C}$ in $70 \mu \mathrm{l}$ of the first reagent (Tris $25 \mathrm{mmol} / \mathrm{l}, \mathrm{KCl} 150 \mathrm{mmol} / \mathrm{l}, \mathrm{MgCl}_{2} 20 \mathrm{mmol} / \mathrm{l}$, EDTA $2 \mathrm{mmol} / \mathrm{l}$, L-glutamate $40 \mathrm{mmol} / \mathrm{l}, \mathrm{Na}_{2} \mathrm{ATP} 5.6 \mathrm{mmol} / \mathrm{l}$, phosphoenolpyruvate $2.2 \mathrm{mmol} / \mathrm{l}$, pyruvate kinase $3.4 \mathrm{IU} / \mathrm{ml}$, $\mathrm{pH} 8.6$ ), the reaction was triggered by $20 \mu \mathrm{l} 2, \alpha$-aminobutyrate $20 \mathrm{mmol} / \mathrm{l}$ and then stopped after 2, 4 or $6 \mathrm{~min}$ (depending on the aliquot) by adding sulfo-5-salicylic acid. The slope of production of $\gamma$-glutamyl aminobutyrate, measured by LC-MS, corresponded to the catalytic activity, and the results were expressed as IU/mg protein.

\section{Real-time PCR mRNA quantification}

Total RNA was isolated from fibroblasts by the total RNA isolation kit (Rneasy mini kit; Qiagen, Courtaboeuf, France). Reverse transcription was performed with $1 \mu \mathrm{g}$ total RNA for each condition with a first-strand cDNA synthesis kit (Amersham, Orsay, France). Human-specific primers were used for $\beta$-actin, the catalytic subunit of $\gamma$-GCL, HO- 1 and COX-2. Primer sequences, gene references and fragment sizes are shown in Table 1 . The specificity of the products 
Table 1. DNA sequences of sense and antisense primers used for quantiative PCR analysis

\begin{tabular}{|c|c|c|c|}
\hline Name & Primers sense/antisense & Amplicon size (bp) & GenBank accession number \\
\hline$\beta$-Actin & $\begin{array}{l}5^{\prime}-\mathrm{TCG}-\mathrm{TGC}-\mathrm{GTG}-\mathrm{ACA}-\mathrm{TTA}-\mathrm{AGG}-\mathrm{AG}-3^{\prime} \\
5^{\prime}-\mathrm{AGC}-\mathrm{ACT}-\mathrm{GTG}-\mathrm{TTG}-\mathrm{GCG}-\mathrm{TAC}-\mathrm{AG}-3^{\prime}\end{array}$ & 262 & NM:001101 \\
\hline Catalytic subunit of $\gamma$-glutyamylcysteine ligase & $\begin{array}{l}5^{\prime}-\mathrm{GAA}-\mathrm{CTG}-\mathrm{GCT}-\mathrm{TGT}-\mathrm{ACA}-\mathrm{TTT}-\mathrm{T}-3^{\prime} \\
5^{\prime}-\mathrm{CAA}-\mathrm{AGG}-\mathrm{AAA}-\mathrm{ATT}-\mathrm{AAC}-\mathrm{GAG}-\mathrm{AG}-3^{\prime}\end{array}$ & 204 & NM:001498 \\
\hline Cyclooxygenase-2 & $\begin{array}{l}5^{\prime}-\mathrm{TCT}-\mathrm{CCT}-\mathrm{TGA}-\mathrm{AAG}-\mathrm{GAC}-\mathrm{TTA}-\mathrm{TG}-3^{\prime} \\
5^{\prime}-\mathrm{CAT}-\mathrm{TGA}-\mathrm{TGG}-\mathrm{TGA}-\mathrm{CTG}-\mathrm{TTT}-\mathrm{TA}-3^{\prime}\end{array}$ & 198 & NM:000963 \\
\hline Haemoxygenase-1 & $\begin{array}{l}5^{\prime}-\mathrm{ACA}-\mathrm{GTT}-\mathrm{GCT}-\mathrm{GTA}-\mathrm{GGG}-\mathrm{CTT}-\mathrm{TA}-3^{\prime} \\
5^{\prime}-\mathrm{CTC}-\mathrm{TGA}-\mathrm{AGT}-\mathrm{TTA}-\mathrm{GGC}-\mathrm{CAT}-\mathrm{TG}-3^{\prime}\end{array}$ & 247 & NM:002133 \\
\hline
\end{tabular}

was demonstrated for each fragment by melting curve analysis and gel electrophoresis.

The following thermocycler program was used for quantitative PCR: 10 min preincubation at $95^{\circ} \mathrm{C}$, followed by 55 cycles of $95^{\circ} \mathrm{C}$ for $15 \mathrm{~s}$, and then $53^{\circ} \mathrm{C}$ for $\mathrm{HO}-1,56^{\circ} \mathrm{C}$ for $\gamma$-GCL, $61^{\circ} \mathrm{C}$ for COX- 2 for $5 \mathrm{~s}$, and $72^{\circ} \mathrm{C}$ for $10 \mathrm{~s}$. $\beta$-Actin was used to standardise the total amount of cDNA. qPCR was carried out on a Light Cycler (Roche) by normalising all cDNA to $\beta$-actin.

\section{Flow cytometry analysis of reactive oxygen species production}

$\mathrm{H}_{2}$ DCF-DA, after deacetylation inside the cell, becomes a probe sensitive to ROS such as $\mathrm{H}_{2} \mathrm{O}_{2}$, the superoxide anion $\left(\mathrm{O}_{2}^{-}\right)$and hydroxyl radicals $(\mathrm{OH})$. The procedure for its use was adapted from that of Carter et al. (1994). After $48 \mathrm{~h}$ and $7 \mathrm{~d}$ of culture, cells were washed twice with PBS, incubated with $2 \mu \mathrm{mol} \mathrm{H}_{2} \mathrm{DCF}-\mathrm{DA} / \mathrm{l}$ in PBS at $37^{\circ} \mathrm{C}$ for $30 \mathrm{~min}$, and subjected to fluorescent flow cytometry analysis (Vantage; Becton Dickinson, Le Pont-de-Claix, France); the oxidation of $\mathrm{H}_{2} \mathrm{DCF}$ was measured, with the excitation set at $488 \mathrm{~nm}$, as an increase in fluorescence at $530 \mathrm{~nm}$ on a log scale for 10 000 events (cell counts).

\section{Lipid peroxidation}

After $48 \mathrm{~h}$ and $7 \mathrm{~d}$ of cell culture, intracellular MDA was measured by LC-MS using a method based on diaminonaphtalene derivatisation, as previously described (Peiro et al. 2005). The quantification was carried out with a dideuterated MDA internal standard, and the derivatives of MDA and d2-MDA were detected at m/z 195.2 and 197.2, respectively. The chromatographic mobile phase (ammonium acetate $5 \mathrm{mmol} / \mathrm{l}$, adjusted at $\mathrm{pH} 1.8$ with formic acid containing $15 \%(\mathrm{v} / \mathrm{v})$ of a methanol-acetonitrile $(1: 1) \mathrm{mix})$ was adjusted to enable full separation of acetaldehyde $(\mathrm{m} / \mathrm{z}=183 \cdot 2)$ and MDA derivatives.

In order to exclude the effect of contaminating lipoperoxides in fatty acid preparations, we measured lipoperoxides in cell culture media, alone as a control or supplemented with $30 \mu \mathrm{mol} / \mathrm{l}$ fatty acids, as previously described (Arab \& Steghens, 2004).

\section{Cell viability}

Fibroblasts were grown with different fatty acids for $48 \mathrm{~h}$ and $7 \mathrm{~d}$, and cells were harvested in DMEM-based incubation media at a density of $1 \times 10^{6}$ cells/well in a standard 96-well plate. The cells were then incubated at $37^{\circ} \mathrm{C}$ for $4 \mathrm{~h}$ with different concentrations of tert-butylhydroperoxide (t-BOOH), followed by incubation at $37^{\circ} \mathrm{C}$ for $3 \mathrm{~h}$ with the tetrazolium salt (3-[4,5-dimethylthiazol2-yl]-2,5-diphenyl tetrazolium bromide). Cell viability was measured as a whole by the tetrazolium salt assay (Mosmann, 1983), according to the protocol proposed by Thermo Electron with its kit assay. Metabolically active cells reduced the dye to purple formazan. Formazan crystals were dissolved in isopropanol with $0.4 \mathrm{M}-\mathrm{HCl}$. Absorbance was measured bichromatically at 570 and $600 \mathrm{~nm}$ using a multiwell plate reader (SpectraMax Model 190; Molecular Devices, Saint Grégoire, France).

\section{Molecular modelling of fatty acids}

Conformation studies were achieved on a PC workstation using the software package Sybyl 7.0 for Linux (Tripos Associates Inc., St Louis, MO, USA). A conformational grid search was performed on each PUFA by varying key torsion angles adjacent to double bonds. All the resulting conformations were then classified according to the increasing order of energy values. Conformational analysis of PUFA was achieved by calculating the energy of conformations obtained by relative variation of key torsion angles $\omega_{1}$ and $\omega_{2}$ for CLA (1296 conformations), $\omega_{1}-\omega_{3}$ for LA (1728 conformations), $\omega_{1}-\omega_{4}$ for LLA and GLA (1296 conformations), $\omega_{1}-\omega_{5}$ for AA and EPA (7776 conformations) and $\omega_{1}-\omega_{6}$ for DHA (46 656 conformations). Conformations with the lowest energy were finally minimised using the Tripos force field to give the representative preferential conformation for each PUFA.

\section{Statistical analysis}

Statistical analysis was carried out with GraphPad software (version 2.1; GraphPad, Deltapoint, Monterey, CA, USA). All data were expressed as means and their standard errors. Comparisons between groups were performed by one-way ANOVA with $95 \%$ CI, followed with Dunnett's multiple range tests.

\section{Results}

\section{Incorporation of fatty acids in cell lipids}

To assess the role of fatty acids in the modulation of thiol redox status in fibroblasts, eight fatty acids representative of the main classes were used: RA, a saturated fatty acid (20:0), OA, a MUFA (18:1n-9), three $n$-6 PUFA (LA $(18: 2 n-6)$, GLA $(18: 3 n-6)$ and AA $(20: 4 n-6))$, two $n-3$ PUFA (LLA (18:3n-3) and EPA $(20: 5 n-3))$ and CLA $(18: 2[9 \mathrm{Z}, 11 \mathrm{E}])$. Total fatty acids were analysed after $48 \mathrm{~h}$ culture in order to check that added fatty acids had been incorporated into cell lipids (Table 2). All fatty acids were highly incorporated, with an increase of at least $100 \%$, except for RA. OA and $n-6$ PUFA displayed a systematic increase in 
Table 2. Fatty acid analysis of human fibroblasts supplemented with of each fatty acid ( $30 \mu \mathrm{mol} / \mathrm{l})$ for $48 \mathrm{~h}$ (Mean values with their standard errors for three determinations)

\begin{tabular}{|c|c|c|c|c|c|c|c|c|c|c|c|c|}
\hline & \multicolumn{2}{|c|}{ Solvent control } & \multicolumn{2}{|c|}{$\begin{array}{c}\gamma \text {-Linolenic acid } \\
(\mathrm{C} 20: 3 n-6) \\
(\mu \mathrm{mol} / / \mathrm{l} \text { per } \\
\text { million cells })\end{array}$} & \multicolumn{2}{|c|}{$\begin{array}{c}\text { Arachidonic } \\
\text { acid }(\mathrm{C} 20: 4 n-6) \\
(\mu \mathrm{mol} / / \mathrm{per} \\
\text { million cells })\end{array}$} & \multicolumn{2}{|c|}{$\begin{array}{c}\alpha \text {-Linolenic acid } \\
(\mathrm{C} 18: 3 n-3) \\
(\mu \mathrm{mol} / \mathrm{l} \text { per } \\
\text { million cells })\end{array}$} & \multicolumn{2}{|c|}{$\begin{array}{c}\text { EPA (C20:5n-3) } \\
(\mu \mathrm{mol} / / \mathrm{per} \\
\text { million cells })\end{array}$} & \multicolumn{2}{|c|}{$\begin{array}{c}\text { Conjugated } \\
\text { linoleic acid } \\
(\mathrm{C} 18: 2[9 \mathrm{Z}, \\
11 \mathrm{E}])(\mu \mathrm{mol} / \mathrm{l} \\
\text { per million cells) }\end{array}$} \\
\hline & Mean & SE & Mean & SE & Mean & SE & Mean & SE & Mean & SE & Mean & SE \\
\hline C14:0 & $8 \cdot 5$ & 0.02 & $10 \cdot 2$ & 1.42 & $19 \cdot 4$ & $5 \cdot 16$ & $17 \cdot 3$ & 0.66 & $8 \cdot 6$ & $1 \cdot 18$ & $7 \cdot 5$ & 0.21 \\
\hline C16:0 & 86.5 & $4 \cdot 28$ & $94 \cdot 1$ & 14.95 & $89 \cdot 2$ & $5 \cdot 46$ & $75 \cdot 3$ & 1.53 & $81 \cdot 8$ & 11.62 & $85 \cdot 2$ & $2 \cdot 81$ \\
\hline C16:1n-7c & $10 \cdot 7$ & 1.03 & 8.6 & 1.63 & $7 \cdot 3$ & 0.64 & $6 \cdot 3$ & 0.2 & $9 \cdot 2$ & $1 \cdot 29$ & 7.9 & 0.26 \\
\hline C17:0 & 3.5 & 0.5 & $4 \cdot 1$ & 0.86 & $3 \cdot 1$ & 0.23 & $2 \cdot 8$ & 0.17 & $3 \cdot 9$ & 0.55 & 4,0 & 0.13 \\
\hline C18:0 & $48 \cdot 9$ & 6.58 & $50 \cdot 0$ & 11.6 & $48 \cdot 3$ & $4 \cdot 88$ & $43 \cdot 4$ & $3 \cdot 87$ & $49 \cdot 6$ & $6 \cdot 76$ & $54 \cdot 1$ & 1.78 \\
\hline C18: $1 n-9 c$ & 69.9 & 11.61 & $55 \cdot 7$ & $13 \cdot 13$ & $59 \cdot 8$ & $9 \cdot 03$ & $54 \cdot 4$ & 3.44 & $62 \cdot 7$ & $8 \cdot 13$ & $58 \cdot 3$ & 1.79 \\
\hline C18: $1 n-7 c$ & $18 \cdot 4$ & $2 \cdot 36$ & $15 \cdot 0$ & $3 \cdot 7$ & $12 \cdot 9$ & $1 \cdot 76$ & $10 \cdot 2$ & 0.58 & $16 \cdot 1$ & $2 \cdot 08$ & $20 \cdot 3$ & 0.66 \\
\hline C18:2n-6 & $10 \cdot 3$ & 1.9 & $9 \cdot 1$ & $1 \cdot 79$ & $15 \cdot 5$ & $7 \cdot 84$ & $19 \cdot 6$ & $1 \cdot 21$ & $11 \cdot 1$ & 1.53 & $10 \cdot 9$ & 0.31 \\
\hline C18:3n-6 & 1.6 & 0.22 & $12 \cdot 2$ & $2 \cdot 33$ & 2.6 & 0.28 & $1 \cdot 32$ & 0.05 & $1 \cdot 7$ & 0.23 & $1 \cdot 3$ & 0.04 \\
\hline C18:3n-3 & 0.22 & 0.02 & 0.2 & 0.04 & 0.17 & 0.01 & $13 \cdot 6$ & 0.84 & 0.4 & 0.05 & 0.2 & 0.02 \\
\hline$C 20: 3 n-6$ & $10 \cdot 4$ & 1.87 & 34.4 & 8.46 & 8.6 & 1.46 & $7 \cdot 4$ & 0.6 & $8 \cdot 3$ & $1 \cdot 14$ & 8.9 & 0.29 \\
\hline$C 20: 4 n-6$ & 33.6 & $6 \cdot 2$ & $42 \cdot 5$ & 8.63 & $48 \cdot 2$ & $5 \cdot 26$ & $25 \cdot 1$ & 2.05 & $27 \cdot 3$ & $3 \cdot 36$ & 34.6 & 1.47 \\
\hline$C 20: 5 n-3$ & $9 \cdot 8$ & 3.92 & 0.9 & 0.29 & $1 \cdot 6$ & 0.41 & $13 \cdot 0$ & 0.55 & $18 \cdot 4$ & $2 \cdot 27$ & $6 \cdot 1$ & 2.56 \\
\hline $\mathrm{C} 22: 4 n-6$ & 2.5 & 0.94 & $6 \cdot 9$ & $2 \cdot 07$ & $11 \cdot 3$ & 3.23 & $1 \cdot 3$ & 0.2 & 2.5 & 0.36 & 3.7 & 0.21 \\
\hline $\mathrm{C} 22: 5 n-6$ & $1 \cdot 18$ & 0.19 & 1.6 & 0.36 & $2 \cdot 8$ & 0.4 & 0.8 & 0.03 & 0.8 & 0.09 & $1 \cdot 2$ & 0.06 \\
\hline $\mathrm{C} 22: 5 n-3$ & $7 \cdot 3$ & 3.04 & $6 \cdot 3$ & $2 \cdot 13$ & $6 \cdot 1$ & 2.55 & 8.6 & 0.91 & $24 \cdot 3$ & $3 \cdot 1$ & $11 \cdot 0$ & 0.48 \\
\hline $\mathrm{C} 22: 6 n-3$ & $14 \cdot 3$ & 3.57 & $10 \cdot 6$ & $2 \cdot 69$ & $8 \cdot 6$ & $2 \cdot 13$ & 6.5 & 0.57 & $9 \cdot 8$ & $1 \cdot 29$ & $15 \cdot 7$ & 0.52 \\
\hline
\end{tabular}

their content and in that of their elongation products associated with a decrease in $n-3$ PUFA content.

For $n$-3 PUFA, LLA supplementation increased EPA content, whereas EPA supplementation had no effect on DHA. Furthermore, these results showed that PUFA $n-6$ elongation was more efficient than that of $n-3$ PUFA.

It is noteworthy that CLA supplementation did not give rise to any changes in fatty acid content.

\section{Fatty acid supplementation and lipoperoxides}

The concentrations of lipoperoxides in the cell culture medium alone or supplemented with each fatty acid were ( $\mu \mathrm{mol} / \mathrm{l}$ ): 1.9 (SE 0.15) for controls, 1.9 (SE 0.15) for RA, 2.0 (SE 0.04) for oleic acid, 1.9 (SE 0.15) for LLA, 1.9 (SE $0 \cdot 10$ ) for LLA, $2 \cdot 2$ (SE 0.15) for GLA, $2 \cdot 1$ (SE 0.12) for AA, $2 \cdot 0$ (SE 0.18) for LLA, 2.2 (SE 0.16) for EPA and 2.1 (SE $0 \cdot 12$ ) for CLA ( $n$ 3). We can therefore exclude the hypothesis that lipoperoxides are responsible for the biological effects we have described.

\section{Arachidonic acid and conjugated linoleic acid induce glutathione synthesis}

Thiol redox status was assessed by measuring cell GSH content and $\gamma$-GCL activity. OA, LA and RA were tested and had no effect on thiol redox status.

During the first $48 \mathrm{~h}, \mathrm{AA}$ and CLA induced a strong antioxidant response by increasing intracellular GSH (more than $100 \%$ for CLA, Fig. 1), associated with an activation of $\gamma$-GCL (Fig. 2(A)). The activation and induction of the $\gamma$-GCL enzyme suggests a response against oxidative conditions, as confirmed by a 3 -fold increase in mRNA expression by AA and CLA. Other fatty acids had no effect on the antioxidant response (Fig. 2(B))

After $7 \mathrm{~d}$ supplementation, AA and CLA maintained their effects by increasing GSH content and $\gamma$-GCL activity, but with a non-significant increase in the GSH level for CLA. GLA, LLA and EPA activated $\gamma$-GCL with no increase in intracellular GSH. Analysis of the mRNA expression level for the catalytic subunit of $\gamma$-GCL confirmed the induction (3-4-fold) for these three fatty acids (Fig. 2).

\section{Measurement of intracellular reactive oxygen species}

GSH is known as the main intracellular antioxidant, and it is often assumed that its content maintains the redox status of the cell; in this way, it is related to intracellular ROS levels. For this reason, intracellular ROS production was assessed in cells supplemented with fatty acids: OA, LA and RA were tested and had no influence.

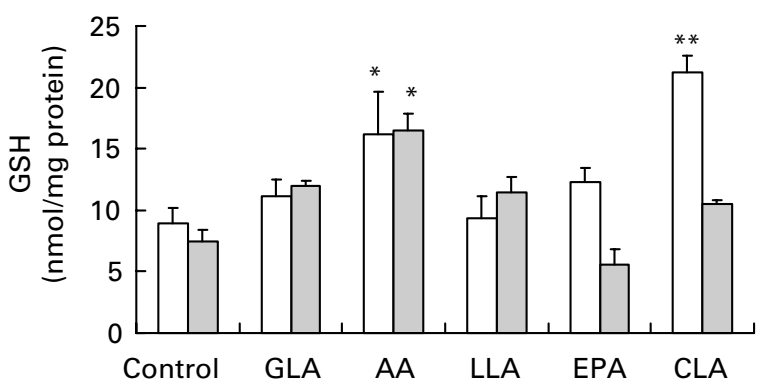

Fig. 1. Glutathione (GSH) content measured in total cell lysate after $48 \mathrm{~h}$ ( $\square$ ) and $7 d(\square)$ of supplementation with different fatty acids. Data are expressed as means and with their standard errors indicated by vertical bars $(n 4)$. GLA, $\gamma$-linolenic acid; AA, arachidonic acid; LLA, $\alpha$-linolenic acid; CLA, conjugated linoleic acid. Mean values were significantly different from those of the control group: ${ }^{*} P<0.05,{ }^{* *} P<0.01$. 
(A)

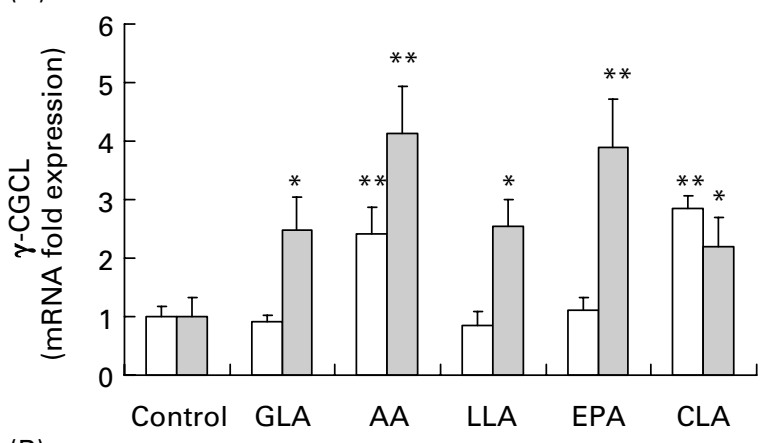

(B)

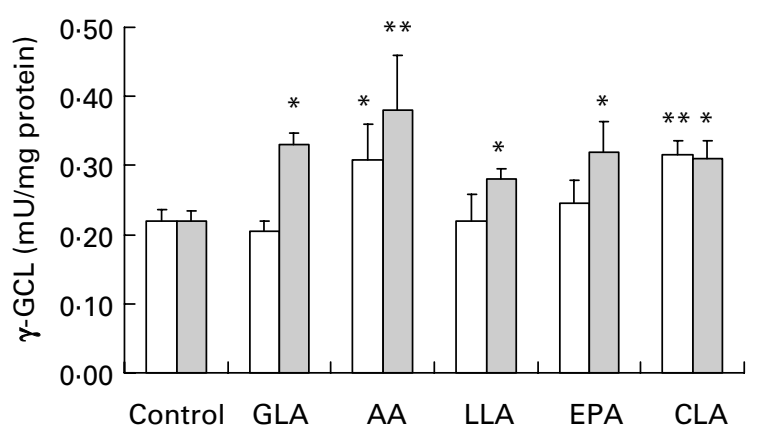

Fig. 2. mRNA expression level for the catalytic subunit of $\gamma$-glutamylcysteine ligase $(\gamma-\mathrm{GCL})(\mathrm{A})$ and the catalytic activity of $\gamma$-GCL (B). Data are expressed as means with their standard errors shown by vertical bars $(n 4)$. $\square, 48 \mathrm{~h}$; $\square$, 7d. GLA, $\gamma$-linolenic acid; AA, arachidonic acid; LLA, $\alpha$-linolenic acid; CLA, conjugated linoleic acid. Mean values were significantly different from those of the control group: ${ }^{*} P<0.05,{ }^{* *} P<0.01$.

At $48 \mathrm{~h}$, flow cytometry analysis showed a $40 \%$ reduction in ROS level by AA, CLA and EPA (in comparison with the solvent control), associated with increased GSH, except for EPA. LLA and GLA had no effect. At $7 \mathrm{~d}$, GSH induction failed to maintain a lowered $\mathrm{H}_{2}$ DCF oxidation in the cells supplemented with AA. With GLA, exceptionally high ROS production was detected $(300 \%)$, although GLA was inactive during the first $48 \mathrm{~h}$. Furthermore, LLA and EPA induced the same level of ROS as that of AA (Fig. 3).

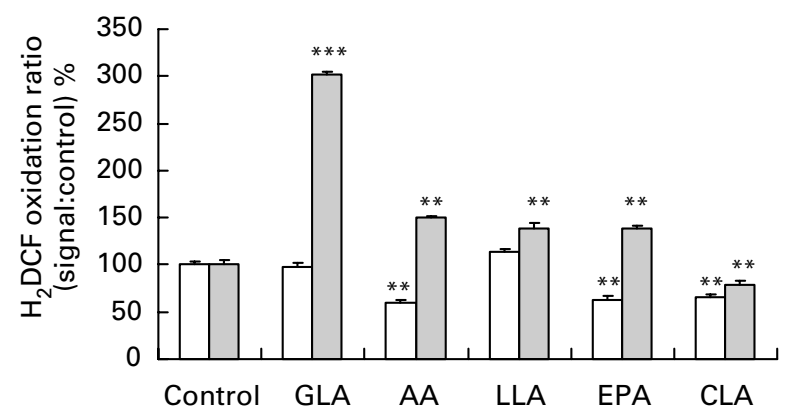

Fig. 3. Evaluation of reactive oxygen species by dichlorofluorescein (DCF) fluorescence flow cytometry analysis of cell suspensions after incubation with different fatty acids for $48 \mathrm{~h}(\square)$ and $7 \mathrm{~d}(\square)$. Flow cytometry analysis was carried out on $1 \times 10^{5}$ cells. In each experiment, conjugated linoleic acid (CLA) was the only fatty acid to induce a significant decrease in reactive oxygen species at $48 \mathrm{~h}$ and $7 \mathrm{~d}$. Data are expressed as means, with their standard errors shown by vertical bars of the relative fluorescent cell number (signal:control \%; ( $n$ 3). GLA, $\gamma$-linolenic acid; AA, arachidonic acid; LLA, $\alpha$ linolenic acid. Mean values were significantly different from those of the control group: ${ }^{* *} P<0.01,{ }^{* * \star} P<0.001$.
Association of haemoxygenase-1 and cyclooxygenase-2 induction with lipoperoxidation

HO-1, formerly known as heat shock protein 32 , is the inducible form of $\mathrm{HO}$, implicated in the cell response against oxidative damage. It is also considered to be a good biomarker of the antioxidant response. Lipid peroxidation is a biomarker of oxidative damage. Thus, the association of this biomarker with HO-1 mRNA induction seems to confirm the increase in oxidative status. In addition, Uchida and colleagues reported that 4-hydroxynonenal, a lipid peroxidation byproduct, could be responsible for the elevation of COX-2 mRNA (Kumagai et al. 2004), and we could hypothesise that an induction of HO-1 and an increase in MDA are suitable conditions for COX-2 induction.

After $48 \mathrm{~h}$, lipoperoxidation did not increase, whatever the fatty acid used, whereas after $7 \mathrm{~d}$, EPA was the strongest inducer of lipid peroxidation (MDA 233 (SE 4.17) pM/mg protein), with significant and similar, but lower, lipoperoxidation for AA, GLA and LLA (about $130 \mathrm{pM} / \mathrm{mg}$ protein; Fig. 4). In this context, the quantification of the mRNA level of HO1 showed a 3-fold induction for EPA and a lower but significant induction for GLA, AA and LLA (Fig. 5).

At 48 hours as well as at $7 \mathrm{~d}$, CLA did not modify the MDA content or the HO-1 and COX-2 mRNA levels (Fig. 6). It should be noted that OA, LA and RA had no effect on either lipoperoxidation or HO-1 and COX-2 mRNA expression.

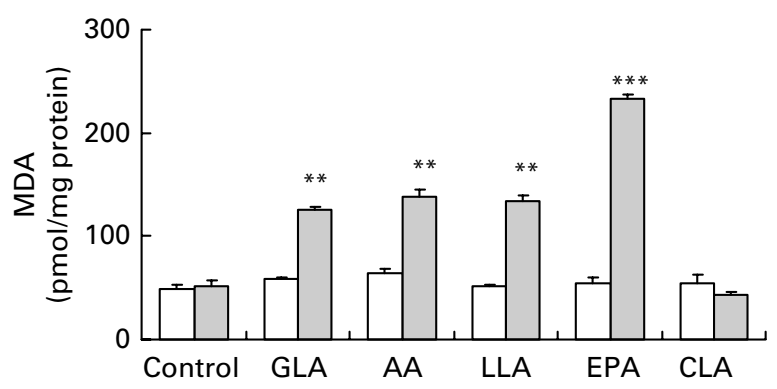

Fig. 4. Lipoperoxidation measured as true malondialdehyde (MDA) cell content after $48 \mathrm{~h}(\square)$ and $7 \mathrm{~d}(\square)$ of fatty acid supplementation. Data are expressed as means with their standard errors shown by vertical bars $(n 3)$. GLA, $\gamma$-linolenic acid; AA, arachidonic acid; LLA, $\alpha$-linolenic acid; CLA, conjugated linoleic acid. Mean values were significantly different from those of the control group: ${ }^{* *} P<0.01,{ }^{* *} P<0.001$.

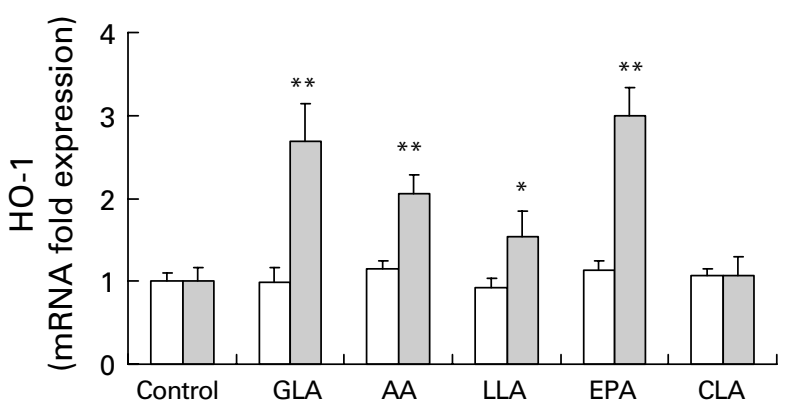

Fig. 5. Haemoxygenase-1 (HO-1) mRNA expression level. Data are expressed as means with their standard errors indicated by vertical bars ( $n$ 3). $\square$, 48h; $\square, 7$ d. GLA, $\gamma$-linolenic acid; AA, arachidonic acid; LLA, $\alpha$-linolenic acid; CLA, conjugated linoleic acid. Mean values were significantly different from those of the control group: ${ }^{\star} P<0.05$, ${ }^{\star \star} P<0.01$. 


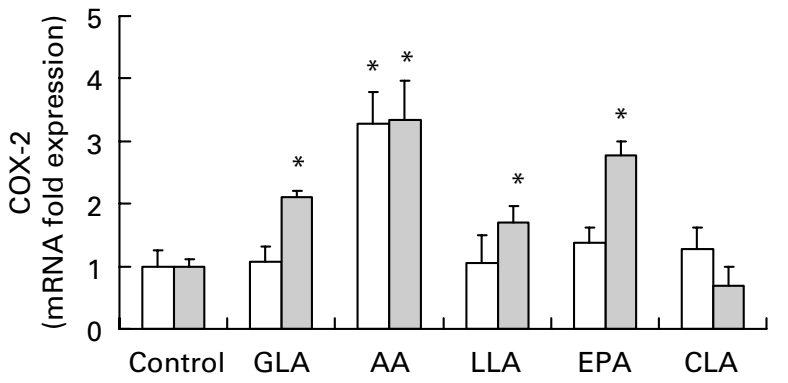

Fig. 6. mRNA expression level of cyclooxygenase-2 (COX-2) in cells supplemented with each fatty acid. at $48 \mathrm{~h}(\square)$ and $7 \mathrm{~d}(\square)$. Data are expressed as means with their standard errors indicated by vertical bars $(n 3)$. GLA, $\gamma$ linolenic acid; AA, arachidonic acid; LLA, $\alpha$-linolenic acid; CLA, conjugated linoleic acid. Mean values were significantly different from those of the control group: ${ }^{\star} P<0.05$

\section{Conjugated linoleic acid protects cells from oxidative stress}

In order to compare the potential protection of different fatty acids against $\mathrm{t}-\mathrm{BOOH}$-induced oxidative stress, we assessed cell viability by the methyl tetrazolium salt test after $48 \mathrm{~h}$ and $7 \mathrm{~d}$ culture with different fatty acids. As shown in Table 3, CLA was the only PUFA able to enhance cell resistance against oxidative stress at $48 \mathrm{~h}$ as well as at $7 \mathrm{~d}$; cell resistance increased to $130 \%$, compared with the control at $48 \mathrm{~h}$ and $7 \mathrm{~d}$, and was associated with a high GSH cell content or GCL activity. Conversely, after $7 \mathrm{~d}$, cell resistance was significantly decreased with GLA (20\%), AA (15\%) and EPA (27\%). Cell susceptibility to t-BOOH seems to be related to intracellular MDA cell content.

\section{Discussion}

In the present report, we investigated the effect of several fatty acids on the cellular antioxidant response and on lipoperoxidation. Fatty acid supplementation increased their concentration in the cells; the present results showed that the elongation products of fatty acids increased, except for EPA, which did not modify DHA content. Conversely, we have previously shown that DHA supplementation increased EPA cell content (Arab et al. 2006). The results obtained with GLA, LA and AA suggest that $n$-6 elongation is more efficient than $n$-3 PUFA elongation in human fibroblasts. It is worth noting that CLA supplementation

Table 3. Tert-butylhydroperoxide (t-BOOH) cytotoxicity test $\left(E_{50} \dagger\right)$ after incubation of cells with different fatty acids for $48 \mathrm{~h}$ and $7 \mathrm{~d}$

(Mean values with their standard errors for three separate experiments)

\begin{tabular}{llllll}
\hline & \multicolumn{3}{c}{ t-BOOH EC ${ }_{50}(\mathrm{mmol} / \mathrm{l})$} \\
\cline { 2 - 3 } \cline { 5 - 6 } Time of fatty acid incubation & \multicolumn{2}{c}{$48 \mathrm{~h}$} & & \multicolumn{2}{c}{$7 \mathrm{~d}$} \\
\cline { 2 - 3 } \cline { 5 - 6 } & Mean & SE & & Mean & SE \\
\hline Control & 0.64 & 0.01 & & 0.63 & 0.01 \\
$\gamma$-Linolenic acid & 0.66 & 0.02 & & $0.52^{*}$ & 0.02 \\
Arachidonic acid & 0.65 & 0.02 & & $0.55^{*}$ & 0.02 \\
$\alpha$-Linolenic acid & 0.67 & 0.01 & & 0.71 & 0.01 \\
EPA & 0.69 & 0.01 & & $0.47^{*}$ & 0.01 \\
Conjugated linoleic acid & $0.84^{*}$ & 0.02 & & $0.84^{*}$ & 0.03
\end{tabular}

Mean values were significantly different from those of the control group: ${ }^{*} P<0.05$. $\dagger E C_{50}$, the concentration of a compound that is required to obtain $50 \%$ cell death. led to a lack of change in fatty acid content, suggesting that this effect uses a different signalling pathway.

The modulation of redox status of the cells appears to be a cytoprotective strategy to reduce oxidative damage, and we showed that GSH synthesis is upregulated by AA and CLA, mainly through an induction of $\gamma$-GCL: an induction of $\gamma$-GCL is characteristic of an antioxidant response (Lee et al. 2003; Rahman, 2005), as previously demonstrated with different compounds such as DHA and sulfaraphane (Gao et al. 2001; Kim et al. 2003; Arab et al. 2006). So we tested the hypothesis that other PUFA could induce an antioxidative response and could explain their beneficial effect in preventing oxidative damage (Manna et al. 1999; Suh et al. 2004). It is noteworthy that the results in Table 2 are for total cell fatty acids (i.e. mainly fatty acids in membrane phospholipids) and that GLA, a precursor of AA, unlike AA, is unable to induce GSH content and other protective enzymes. We may thus suppose that the fatty acids which efficiently induce an antioxidant response are in a 'free form'.

As a consequence of their chemical structure, which is very sensitive to free radicals, it is assumed that the oxidation of $n-3$ PUFA generates byproducts such as 4-hydroxynonenal and MDA, which seem to play a role in the exacerbation of oxidative damage. Conversely, EPA is often described as a potential cytoprotective agent against oxidative stress by downregulating proinflammatory genes, interleukin- 8 and COX-2 (Obata et al. 1999; Storey et al. 2005). For EPA, in our model, the present results enable us to exclude the enhancement of thiol redox status to explain this cytoprotection as well as the downregulation of genes such as COX-2. However, the ability of EPA and other $n$ - 3 PUFA to induce apoptosis and tumour suppression through lipid peroxidation is well described (Lynch et al. 2003; Utomo et al. 2004; Ng et al. 2005) and is in excellent agreement with the large production of MDA detected in our human fibroblasts and in an MRC5 cell culture model (data not shown). We suggest that this lipoperoxidation may be a protective mechanism against malignancy and carcinogenesis (Maheo et al. 2005).

The presence of protein-bound lipoperoxidation products has been reported in many chronic diseases in man, including atherosclerosis and neurodegenerative disorders (Terasawa et al. 2000; Liu et al. 2005). On the one hand, lipoperoxidation is associated with an induction of $\mathrm{HO}-1$, an association reported to be a defence mechanism during oxidative injury (Hill-Kapturczak et al. 2003; Kim et al. 2005). On the other hand, the involvement of $\mathrm{COX}-2$ in lipoperoxidation has been demonstrated by several studies, but the effect of lipoperoxidation products on its expression is less known. In addition, some reports have indicated that 4-hydroxynonenal induces COX-2 mRNA and promotes oxidative damage (Nanji et al. 2001; Ishii et al. 2004; Kumagai et al. 2004). COX-2 might then, via lipoperoxidation, mediate the formation of DNA adducts and increase the risk of tumorigenesis (Lee et al. 2005). Taking these relations into account, we tested the hypothesis that lipoperoxidation products might be involved in the upregulation of COX-2 and compared the level of MDA, a terminal lipoperoxidation product, with ROS production and COX-2 and HO-1 induction. Except for CLA, the present results showed that a high production of MDA was associated with a high induction of HO-1, COX-2 and ROS production. The fact that COX-2 is suggested to be 

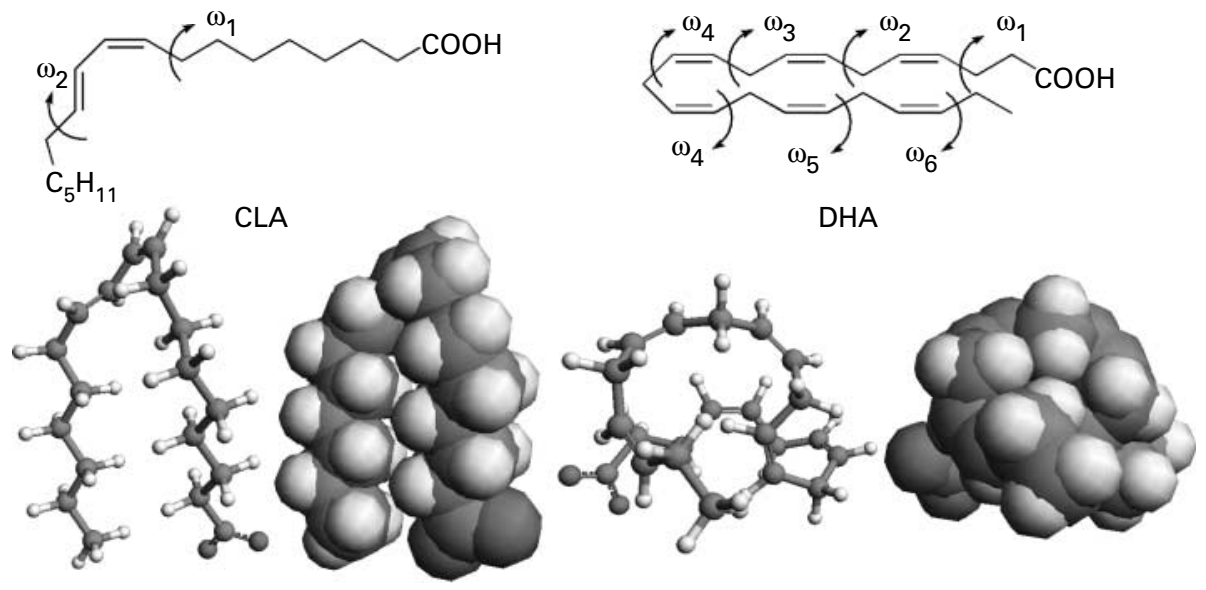

Fig. 7. Molecular modelling study of PUFA (not shown for arachidonic acid, EPA, linoleic acid, $\alpha$-linolenic acid or $\gamma$-linolenic acid): key torsion angles $\omega_{1}-\omega_{2}$ (conjugated linoleic acid; CLA). $\omega_{1}-\omega_{6}$ (DHA) was employed for the conformational analysis and visualisation of the representative preferential conformations for the PUFA. CLA and DHA are shown on ball and stick and spacefill representations. Representative preferential conformations of PUFA can be described by the shape of the overall structure. CLA adopts a 'hairpin' conformation owing to the intramolecular hydrophobic interactions of the two alkyl chains on either side of the double bonds, whereas EPA and DHA adopt globular conformations. The preferential conformation of arachidonic acid is intermediate between a hairpin and a globular shape owing to a more folded structure compared with CLA.

auto-inducible by its preferential substrate AA could explain the elevation in COX-2 mRNA, detected as soon as $48 \mathrm{~h}$, when cells are supplemented with AA.

The measurement of cell viability in the presence of t-BOOH was used as a further test to check cell protection: only CLA protected cells against oxidative damage induced by t-BOOH (Table 3). For CLA, this protection seems to be mediated by the high level of $\mathrm{GSH}$; the same protective effect was found for DHA $\left(\mathrm{EC}_{50} 0.95\right.$ (SE 0.03) $\mathrm{mmol} / \mathrm{l}$; data not shown), which also induced a strong antioxidant response associated with a 4 -fold increase in GSH at $7 \mathrm{~d}$ (Arab et al. 2006). The elevated MDA content and the induction of COX-2, associated with a lower increase in GSH in cells supplemented with AA, could explain the absence of a protective effect of GSH against oxidative damage. Cell viability might be dependent on a balance between thiol redox status and lipoperoxidation. The model with GLA and EPA is in agreement with this hypothesis, and further work is necessary to confirm whether there is a link between lipoperoxidation and COX-2 induction.

CLA $(18: 2[9 \mathrm{Z}, 11 \mathrm{E}])$ is a member of the linoleic acid isomers, described in the 1990 s as potent bioactive molecules against insulin resistance and recently as agonists of PPAR- $\gamma$ (Ryder et al. 2001; Kuniyasu et al. 2006). We used CLA $(18: 2[9 \mathrm{Z}, 11 \mathrm{E}]$ because it is the most abundant isomer in the diet of man. The study of the dose effect for AA and CLA showed that both were already significantly active at $6 \mu \mathrm{mol} / 1$ (Supplementary Fig.) but with a different slope for each fatty acid. In addition, CLA induced GSH synthesis, without any induction of ROS production (even at 4 or $8 \mathrm{~h}$; data not shown). This demonstrates that GSH synthesis was induced through a mechanism independent of ROS production. As the ability of CLA to enhance GSH content relies on $\gamma$-GCL induction, and the main inducers of this activity are ROS and PPAR- $\gamma$, our results suggest that the induction of $\gamma$-GCL by CLA, unlike other PUFA, could be mediated through PPAR- $\gamma$.
To explain this specific behaviour of CLA, a structureactivity relationship was attempted through a conformational study of PUFA. The molecular modelling study was carried out in order to delineate preferential conformations that PUFA would adopt in a biological medium. This conformation analysis of PUFA clearly shows the following:

1. Double bonds induce the presence of curved regions.

2. The packed conformation that allows intramolecular hydrophobic interactions increases with the degree of unsaturation of the PUFA. The position of the double bonds also enhances these interactions in GLA, for example, compared with LLA (two double bonds each).

3. Particular preferential conformations are remarkable for CLA (hairpin shape) and for AA, EPA and DHA (globular shape; Fig. 7).

Except for GLA, whose conformation is difficult to classify, this study suggests that the particular hairpin conformation of CLA (similar to that of the isomer trans-10, cis-12; data not shown) may allow specific hydrophobic interactions with proteins and could explain its specific interaction with PPAR- $\gamma$.

In the present report, we showed that, of the eight fatty acids tested, AA and CLA were the most potent inducers of GSH synthesis, and only CLA had a protective action, due to GSH synthesis without lipoperoxidation. The supposed relationships between fatty acid structures and their actions need to be explored to clarify the role of CLA and its isomers in modulating the redox status of the cell. The protective effect of a CLA-rich diet has already been described and could be related to the enhancement of the thiol redox status described here.

\section{Acknowledgements}

We thank Sarah Somerville (IARC, Lyon, France) for careful editing of the English, and Dr Mireille Serres and Dr Sandra Trompezinski (INSERM, EA 3732) for flow cytometry analysis. 


\section{References}

Arab K, Rossary A, Flourie F, Tourner Y \& Steghens JP (2006) Docosahexaenoic acid enhances the antioxidant response of human fibroblasts by upregulating $\gamma$-glutamyl-cysteinyl ligase and glutathione reductase. Br J Nutr 95, 18-26.

Arab K \& Steghens JP (2004) Plasma lipid hydroperoxides measurement by an automated xylenol orange method. Anal Biochem 325, $158-163$.

Carter WO, Narayanan PK \& Robinson JP (1994) Intracellular hydrogen peroxide and superoxide anion detection in endothelial cells. J Leukoc Biol 55, 253-258.

Chan DC, Watts GF, Mori TA, Barrett PH, Redgrave TG \& Beilin LJ (2003) Randomized controlled trial of the effect of n-3 fatty acid supplementation on the metabolism of apolipoprotein B-100 and chylomicron remnants in men with visceral obesity. Am J Clin Nut. 77, 300-307.

Chik K, Flourie F, Arab K \& Steghens JP (2005) Kinetic measurement by LC/MS of gamma-glutamylcysteine ligase activity. $J$ Chromatogr B 827, 32-38.

Gao X, Dinkova-Kostova AT \& Talalay P (2001) Powerful and prolonged protection of human retinal pigment epithelial cells, keratinocytes, and mouse leukemia cells against oxidative damage: the indirect antioxidant effects of sulforaphane. PNAS 98, $15221-15226$

Higdon JV, Liu J, Du SH, Morrow JD, Ames BN \& Wander RC (2000) Supplementation of postmenopausal women with fish oil rich in eicosapentaenoic acid and docosahexaenoic acid is not associated with greater in vivo lipid peroxidation compared with oils rich in oleate and linoleate as assessed by plasma malondialdehyde and F(2)-isoprostanes. Am J Clin Nutr 72, 714-722.

Hill-Kapturczak N, Voakes C, Garcia J, Visner G, Nick HS \& Agarwal A (2003) A cis-acting region regulates oxidized lipidmediated induction of the human heme oxygenase- 1 gene in endothelial cells. Arterioscler Thromb Vasc Biol 23, 1416-1422.

Ishii T, Itoh K, Ruiz E, Leake DS, Unoki H, Yamamoto M \& Mann GE (2004) Role of Nrf2 in the regulation of CD36 and stress protein expression in murine macrophages: activation by oxidatively modified LDL and 4-hydroxynonenal. Circ Res 94, 609-616.

Jump DB (2002) The biochemistry of n-3 polyunsaturated fatty acids. $J$ Biol Chem 277, 8755-8758.

Kim BR, Hu R, Keum YS, Hebbar V, Shen G, Nair SS \& Kong AN (2003) Effects of glutathione on antioxidant response elementmediated gene expression and apoptosis elicited by sulforaphane. Cancer Res 63, 7520-7525.

Kim YS, Zhuang H, Koehler RC \& Dore S (2005) Distinct protective mechanisms of HO-1 and HO-2 against hydroperoxide-induced cytotoxicity. Free Radic Biol Med 38, 85-92.

Kumagai T, Matsukawa N, Kaneko Y, Kusumi Y, Mitsumata M \& Uchida K (2004) A lipid peroxidation-derived inflammatory mediator: identification of 4-hydroxy-2-nonenal as a potential inducer of cyclooxygenase-2 in macrophages. J Biol Chem 279, 48389-48396.

Kuniyasu H, Yoshida K, Sasaki T, Sasahira T, Fujii K \& Ohmori H (2006) Conjugated linoleic acid inhibits peritoneal metastasis in human gastrointestinal cancer cells. Int J Cancer 118, 571-576.

Laidlaw M \& Holub BJ (2003) Effects of supplementation with fish oilderived n-3 fatty acids and gamma-linolenic acid on circulating plasma lipids and fatty acid profiles in women. Am J Clin Nutr 77, 37-42.

Lee JM, Calkins MJ, Chan K, Kan YW \& Johnson JA (2003) Identification of the NF-E2-related factor-2-dependent genes conferring protection against oxidative stress in primary cortical astrocytes using oligonucleotide microarray analysis. J Biol Chem 278, 12029-12038.

Lee SH, Williams MV, Dubois RN \& Blair IA (2005) Cyclooxygenase-2-mediated DNA damage. J Biol Chem 280, 28337-28346.

Leung L, Kwong M, Hou S, Lee C \& Chan JY (2003) Deficiency of the Nrf1 and Nrf2 transcription factors results in early embryonic lethality and severe oxidative stress. J Biol Chem 278, 48021-48029.

Levonen AL, Landar A, Ramachandran A, Ceaser EK, Dickinson DA, Zanoni G, Morrow JD \& Darley-Usmar VM (2004) Cellular mechanisms of redox cell signalling: role of cysteine modification in controlling antioxidant defences in response to electrophilic lipid oxidation products. Biochem J 378, Pt 2, 373-382.

Liu Q, Smith MA, Avila J, et al. (2005) Alzheimer-specific epitopes of tau represent lipid peroxidation-induced conformations. Free Radic Biol Med 38, 746-754.

Lynch AM, Moore M, Craig S, Lonergan PE, Martin DS \& Lynch MA (2003) Analysis of interleukin-1 beta-induced cell signaling activation in rat hippocampus following exposure to gamma irradiation. Protective effect of eicosapentaenoic acid. J Biol Chem 278, 51075-51084.

Maheo K, Vibet S, Steghens JP, Dartigeas C, Lehman M, Bougnoux P \& Gore J (2005) Differential sensitization of cancer cells to doxorubicin by DHA: A role for lipoperoxidation. Free Radic Biol Med 39, $742-751$.

Manna SK, Kuo MT \& Aggarwal BB (1999) Overexpression of gamma-glutamylcysteine synthetase suppresses tumor necrosis factor-induced apoptosis and activation of nuclear transcription factor-kappa B and activator protein-1. Oncogene 18, 4371-4382.

Meister A (1983) Selective modification of glutathione metabolism. Science 20, 472-477.

Mori TA, Woodman RJ, Burke V, Puddey IB, Croft KD \& Beilin LJ (2003) Effect of eicosapentaenoic acid and docosahexaenoic acid on oxidative stress and inflammatory markers in treated-hypertensive type 2 diabetic subjects. Free Radic Biol Med 35, 772-781.

Mosmann T (1983) Rapid colorimetric assay for cellular growth and survival: application to proliferation and cytotoxicity assays. J Immunol Methods 65, 55-63.

Mukherjee PK, Marcheselli VL, Serhan CN \& Bazan NG (2004) Neuroprotectin D1: a docosahexaenoic acid-derived docosatriene protects human retinal pigment epithelial cells from oxidative stress. PNAS 101, 8491-8496.

Nanji AA, Jokelainen K, Fotouhinia M, Rahemtulla A, Thomas P, Tipoe GL, Su GL \& Dannenberg AJ (2001) Increased severity of alcoholic liver injury in female rats: role of oxidative stress, endotoxin, and chemokines. Am J Physiol Gastrointest Liver Physiol 281, G1348-G1356.

Ng Y, Barhoumi R, Tjalkens RB, Fan YY, Kolar S, Wang N, Lupton JR \& Chapkin RS (2005) The role of docosahexaenoic acid in mediating mitochondrial membrane lipid oxidation and apoptosis in colonocytes. Carcinogenesis 26, 1914-1921.

Obata T, Nagakura T, Masaki T, Maekawa K \& Yamashita K (1999) Eicosapentaenoic acid inhibits prostaglandin D2 generation by inhibiting cyclo-oxygenase-2 in cultured human mast cells. Clin Exp Allergy 29, 1129-1135.

Oostenbrug GS, Mensink RP \& Hornstra G (1994) Effects of fish oil and vitamin $\mathrm{E}$ supplementation on copper-catalysed oxidation of human low density lipoprotein in vitro. Eur J Clin Nutr 48, 895-898.

Peiro G, Alary J, Cravedi JP, Rathahao E, Steghens JP \& Gueraud F (2005) Dihydroxynonene mercapturic acid, a urinary metabolite of 4-hydroxynonenal, as a biomarker of lipid peroxidation. Biofactors 24, 89-96.

Pepe S \& McLennan PL (2002) Cardiac membrane fatty acid composition modulates myocardial oxygen consumption and postischemic recovery of contractile function. Circulation 105, 2303-2308.

Rahman I (2005) Regulation of glutathione in inflammation and chronic lung diseases. Mutat Res 579, 58-80.

Ringborn T, Huss U, Stenholm A, Flock S, Skattebol L, Perera P \& Bohlin L (2001) Cox-2 inhibitory effects of naturally occurring and modified fatty acids. $J$ Nat Prod 64, 745-749.

Ryder JW, Portocarrero CP, Song XM, et al. (2001) Isomer-specific antidiabetic properties of conjugated linoleic acid. Improved 
glucose tolerance, skeletal muscle insulin action, and UCP-2 gene expression. Diabetes 50, 1149-1157.

Smith WL, DeWitt DL \& Garavito RM (2000) Cyclooxygenases: structural, cellular, and molecular biology. Аппи Rev Biochem 69, $145-182$.

Song JH, Fujimoto K \& Miyazawa T (2000) Polyunsaturated (n-3) fatty acids susceptible to peroxidation are increased in plasma and tissue lipids of rats fed docosahexaenoic acid-containing oils. J Nutr 130, 3028-3033.

Steghens JP, Flourie F, Arab K \& Collombel C (2003) Fast liquid chromatography-mass spectrometry glutathione measurement in whole blood: micromolar GSSG is a sample preparation artifact. J Chromatogr B 798, 343-349.

Storey A, McArdle F, Friedmann PS, Jackson MJ \& Rhodes LE (2005) Eicosapentaenoic acid and docosahexaenoic acid reduce UVB- and TNF-alpha-induced IL-8 secretion in keratinocytes and UVB-induced IL-8 in fibroblasts. $J$ Invest Dermatol 124, $248-255$.

Suh JH, Shenvi SV, Dixon BM, Liu H, Jaiswal AK, Liu RM \& Hagen TM (2004) Decline in transcriptional activity of Nrf2 causes agerelated loss of glutathione synthesis, which is reversible with lipoic acid. PNAS 101, 3381-3386.
Terasawa Y, Ladha Z, Leonard SW, Morrow JD, Newland D, Sanan D, Packer L, Traber MG \& Farese RV Jr (2000) Increased atherosclerosis in hyperlipidemic mice deficient in alpha-tocopherol transfer protein and vitamin E. PNAS 97, 13830-13834.

Urata Y, Yamamoto H, Goto S, Tsushima H, Akazawa S, Yamashita S, Nagataki S \& Kondo T (1996) Long exposure to high glucose concentration impairs the responsive expression of gamma-glutamylcysteine synthetase by interleukin-1beta and tumor necrosis factor-alpha in mouse endothelial cells. $J$ Biol Chem 271, $15146-15152$.

Utomo A, Jiang X, Furuta S, Yun J, Levin DS, Wang YC, Desai KV, Green JE, Chen PL \& Lee WH (2004) Identification of a novel putative non-selenocysteine containing phospholipid hydroperoxide glutathione peroxidase (NPGPx) essential for alleviating oxidative stress generated from polyunsaturated fatty acids in breast cancer cells. J Biol Chem 279, 43522-43529.

Wild AC, Moinova HR \& Mulcahy RT (1999) Regulation of gammaglutamylcysteine synthetase subunit gene expression by the transcription factor Nrf2. J Biol Chem 274, 33627-33636.

Wu X, Bishopric NH, Discher DJ, Murphy BJ \& Webster KA (1996) Physical and functional sensitivity of zinc finger transcription factors to redox change. Mol Cell Biol 16, 1035-1046. 